\title{
AS POLÍTICAS PÚBLICAS E A GESTÃO DOCUMENTAL NAS UNIVERSIDADES FEDERAIS DO RIO GRANDE DO SUL
}

\author{
PUBLIC POLICY AND DOCUMENT MANAGEMENT IN \\ FEDERAL UNIVERSITY OF RIO GRANDE DO SUL
}

\author{
Franciele Simon Carpes $^{1}$ e Denise Molon Castanho ${ }^{2}$
}

Recebido em: 18/03/2012

Aprovado em: 23/07/2014

\section{RESUMO}

$\mathrm{O}$ enfoque da pesquisa que resultou neste artigo consiste nas políticas públicas arquivísticas das universidades federais do Rio Grande do Sul. Dessa forma, o objetivo geral da pesquisa foi investigar as políticas públicas arquivísticas voltadas para os arquivos universitários a fim de analisar a sua implementação e as dificuldades encontradas para isso. Para realizar esta investigação, foram selecionadas as três universidades mais antigas do Estado. Os instrumentos de coleta de dados foram aplicados aos arquivistas da instituição responsáveis pela documentação. Os dados coletados foram reunidos e analisados, qualitativamente, e discutidos com base na fundamentação teórica. A discussão e reflexão sobre as políticas públicas arquivísticas voltadas aos arquivos universitários permitem afirmar que as universidades estudadas aplicam em parte as políticas instituídas pelos órgãos arquivísticos nacionais (Conselho Nacional de Arquivos e Arquivo Nacional), pois as consideram insuficientes, apresentando dificuldades na sua implementação. Mesmo assim, as universidades demonstraram interesse em participar do estabelecimento de políticas públicas arquivísticas, tendo efetuado diversas ações nesse sentido.

Palavras-chave: Políticas públicas arquivísticas; Universidades federais; Gestão documental.

\begin{abstract}
The focus of the research that resulted in this article are the archival policies in the federal universities of Rio Grande do Sul. Thus, the objective of the research was to investigate the archival policies targeting the university archives to examine its implementation as well as the difficulties this check. To conduct this research, we selected the three oldest universities of the state. The instruments were applied to the archivists of the institution responsible for documentation. Data were collected and analyzed qualitatively and discussed based on theoretical reasoning. The discussion and debate on public policies aimed at archival university archives, let us state that universities apply to study in part the policies instituted by the national archival agencies (the National Archives and the National Archives) and consider them insufficient, presenting difficulties in its implementation. Even so, universities have expressed interest in participating in the establishment of public policies archival, and many actions are being carried out.
\end{abstract}

Keywords: Public policies archival; Federal universities, Document management

${ }^{1}$ Arquivista da Universidade Federal de Santa Maria (UFSM), Brasil. Especialista em Gestão em Arquivos e mestranda em Patrimônio Cultural da UFSM. E-mail: fran_carpes@yahoo.com.br.

${ }^{2}$ Mestre em Educação pela Universidade Federal de Santa Maria, Brasil. Professora Adjunta do Departamento de Documentação da Universidade Federa de Santa Maria (UFSM).E-mail: molon63@yahoo.com.br. 


\section{Introdução}

Os arquivos das universidades têm sob sua guarda documentos essenciais para a administração da universidade no que diz respeito às atividades de ensino, pesquisa e extensão. Além disso, esses documentos são testemunho da memória da instituição, podendo ser fonte de pesquisa para alunos, professores, historiadores, pesquisadores, entre outros.

As políticas públicas arquivísticas são fundamentais, servem como base para a gestão de documentos, principalmente nos arquivos das instituições públicas, como é o caso das universidades federais. Elas servem como subsídio e orientação para o desenvolvimento das atividades arquivísticas, impulsionando o progresso da arquivística e representando uma garantia do cumprimento do direito de acesso à informação.

Nesse contexto, esta pesquisa teve o objetivo de investigar as políticas públicas arquivísticas voltadas para os arquivos universitários a fim de analisar a sua implementação, bem como verificar as dificuldades encontradas para isso.

\section{Arquivística: suas funções e a ges- tão documental}

A arquivística ou arquivologia é a disciplina que estuda os arquivos, suas funções e sua utilização, agrupando "todos os princípios, normas e técnicas que regem a gestão dos arquivos" (ROUSSEAU; COUTURE, 1998, p. 24). A disciplina tem por objetivo tornar as informações acessíveis aos usuários, por meio do seu tratamento, ou seja, dar acesso às informações contidas nos documentos (CASTANHO; GARCIA; SILVA, 2006).

Os arquivos são os conjuntos de documentos produzidos e recebidos no decorrer das atividades de qualquer pessoa física ou jurídica independentemente do suporte em que se encontram. Para que o arquivo cumpra sua finalidade, deve desenvolver suas funções fundamentadas em teorias e metodolo- gias próprias. Estas, por sua vez, devem estar baseadas nos princípios arquivísticos que "constituem o marco principal da diferença entre a arquivística e as outras 'ciências' documentárias" (BELLOTTO, 2002, p. 20).

A gestão de documentos ou gestão documental é a sequência de procedimentos executados desde a criação do documento até o seu destino final, "com vistas à racionalização e eficiência administrativa, bem como a preservação do patrimônio documental de interesse histórico-cultural" (BERNARDES, 1998, p. 11). A gestão de documentos estabelece políticas que permitem inúmeras vantagens, tais como acesso rápido às informações e melhor organização, controle e integridade dos documentos e dos conjuntos documentais, respeitando os princípios da ordem original e da proveniência. Uma gestão sistêmica, com interação entre os procedimentos da gestão dos documentos garantindo a sua eficiência e a eficácia, só é possível por meio da implementação de um sistema de arquivos. Por sistema de arquivos entende-se o conjunto de arquivos que funcionam de forma integrada para alcançar objetivos comuns (ARQUIVO NACIONAL, 2001).

Dentre os procedimentos da gestão documental, destacam-se as funções arquivísticas: classificação, avaliação e descrição. A classificação, a avaliação e a descrição são consideradas inseparáveis e complementares, segundo a perspectiva da arquivística integrada (LOPES, 1997).

A classificação é a "seqüência de operações que, de acordo com as diferentes estruturas organizacionais, funções e atividades da entidade produtora, visam a distribuir em classes os documentos de um arquivo" (CAMARGO; MACHADO, 2000, p. 24). Esta função arquivística é considerada a operação mais importante, juntamente com a ordenação - disposição física dos documentos -, porque torna possível a realização eficiente de todas as outras funções do arquivo (GONÇALVES, 
1998). A classificação é materializada em um instrumento denominado plano de classificação, esquema que distribui os documentos de um fundo em classes divididas hierarquicamente.

A classificação proporciona bases sólidas para a avaliação dos documentos já que, "ao classificar, se estão fornecendo os meios para se compreender melhor o valor das informações" (LOPES, 1997, p. 95), o que torna possível estabelecer os prazos de guarda e a destinação dos documentos. Lopes ressalta, ainda, que a classificação tem intensas repercussões sobre as demais funções, pois, quando se classifica, produz-se um primeiro nível avaliativo e descritivo.

A avaliação, por sua vez, consiste em identificar valores para os documentos (imediato e mediato) e analisar seu ciclo de vida, com vistas a estabelecer prazos para sua guarda ou eliminação, contribuindo para a racionalização dos arquivos e eficiência administrativa, bem como para a preservação do patrimônio documental (BERNARDES, 1998). Enquanto cumpre a função imediata para a qual foi criado, o documento possui valor primário e deve permanecer no arquivo corrente. Terminado esse prazo, deve ser transferido para o arquivo intermediário, onde é preservado por precaução, pois ainda possui valor primário e aguarda sua destinação final - eliminação ou recolhimento. Os documentos recolhidos, com valor secundário, são mantidos permanentemente nos arquivos históricos ou permanentes. $\mathrm{O}$ instrumento que determina os prazos de guarda e a destinação dos documentos é a tabela de temporalidade, que deve ser aprovada por autoridades competentes e divulgada antes de ser aplicada. A avaliação de documentos de arquivo "é uma etapa decisiva no processo de implantação de políticas de gestão de documentos, tanto nas instituições públicas quanto nas empresas privadas" (BERNARDES, 1998, p. 13). O processo de avaliação documental é complexo e delicado, pois requer abrangência de conhecimentos e o estabelecimento de critérios seguros para a atribuição de valores.

Sob a perspectiva da arquivística integrada, fariam parte de um programa de descrição instrumentos como planos de classificação e tabelas de temporalidade, por exemplo (LOPES, 1997). Assim, a descrição enquanto processo que permite a identificação e a elaboração dos instrumentos de pesquisa, deve iniciar-se na classificação, continuar com a avaliação e intensificar-se nos arquivos permanentes.

Os instrumentos de pesquisa são o "meio que permite a identificação, localização ou consulta a documentos ou a informações neles contidas" (ARQUIVO NACIONAL, 2005, p. 108). Existem vários tipos de instrumentos de pesquisa, tais como guia, inventário, catálogo, índices etc., cada um com sua especificidade.

Atualmente, a elaboração de instrumentos de pesquisa deve remeter-se às normas existentes. Dentre as normas de descrição arquivística, pode-se citar a Norma Geral Internacional de Descrição Arquivística (ISAD $(\mathrm{G})$ ); a Norma Internacional de Registro de Autoridade Arquivística para Entidades Coletivas, Pessoas e Famílias (ISAAR (CPF)), a Norma Internacional para Descrição de Instituições com Acervo Arquivístico (ISDIAH) e a Norma Internacional para Descrição de Funções (ISDF) - publicadas pelo Conselho Internacional de Arquivos (CIA) - e a Norma Brasileira de Descrição Arquivística (NOBRADE) - publicada pelo Conselho Nacional de Arquivos (CONARQ).

A NOBRADE (2006) foi elaborada pela Câmara Técnica de Normalização da Descrição Arquivística (CTNDA) do Conselho Nacional de Arquivos (CONARQ), em conformidade com a ISA$\mathrm{D}(\mathrm{G})$ e a ISAAR (CPF). Após discussão pela comunidade profissional, foi aprovada pelo CONARQ pela Resolução n. ${ }^{\circ} 28$, de 17 de fevereiro de 2009. Como norma brasileira, que contextualiza a descrição arquivística ao cenário nacional, estabelece diretivas para a descrição no Brasil de documentos arquivísticos e tem em vista 
facilitar o acesso e o intercâmbio de informações em âmbito nacional e internacional (CONARQ, 2006).

\section{As políticas públicas arquivísticas}

A política nacional de arquivos compreende os atos, as decisões, as deliberações governamentais e as normas aplicadas à área de arquivos. Jardim (2006, p. 7) conceitua política pública arquivística como:

o conjunto de premissas, decisões e ações - produzidas pelo Estado e inseridas nas agendas governamentais em nome do interesse social - que contemplam os diversos aspectos (administrativo, legal, científico, cultural, tecnológico, etc.) relativos à produção, ao uso e à preservação da informação arquivística de natureza pública e privada.

Sousa (2006) entende as políticas públicas de arquivo como o corpus de normas e diretrizes visando à gestão documental e à proteção especial aos documentos de arquivo; as diretrizes para o funcionamento do Sistema Nacional de Arquivos; a promoção de ações de preservação do patrimônio documental brasileiro; as diretrizes para o treinamento e a capacitação dos recursos humanos; e a garantia do acesso à informação.

O Arquivo Nacional (2001) emprega com o mesmo sentido o termo "política nacional de arquivos". A política nacional de arquivos compreende a definição e adoção de um conjunto de normas e procedimentos técnicos e administrativos para disciplinar as atividades relativas aos serviços arquivísticos da administração pública, trazendo, por consequência, a melhoria dos arquivos públicos (ARQUIVO NACIONAL, 2001). Outras expressões utilizadas são: políticas públicas de arquivos, políticas públicas de informação, políticas informacionais, políticas arquivísticas nacionais etc.

Na definição de Silva (1992), a política nacional de arquivos, consoan- te os princípios teóricos da moderna arquivologia, compreende a definição e a adoção de um conjunto de normas e procedimentos, técnicos e administrativos, para disciplinar as atividades relativas aos arquivos públicos e estimular a organização especial dos arquivos privados. A implementação dessa política necessariamente passa pelo processo de reestruturação da própria administração pública do país e pela redefinição do papel das instituições arquivísticas do poder público (SILVA, 1992). O autor destaca, ainda, que a finalidade dessa política consiste em

assegurar a preservação do patrimônio documental brasileiro e garantir, no que diz respeito aos arquivos públicos, o direito constitucional de acesso as informações governamentais - compatibilizando as questões inerentes à segurança do Estado e da Sociedade e à privacidade dos cidadãos - e, no que tange aos arquivos privados, estimular a pesquisa aos documentos classificados como interesse público e social - resguardando o preceito inviolável da propriedade privada (p. 3).

As primeiras tentativas de estabelecimento de uma política arquivística no Brasil remontam à criação do Sistema Nacional de Arquivos, em 1978 (SOUSA, 2006). Jardim (2003) destaca que há frequentes associações entre políticas arquivísticas e sistema nacional de arquivos. "Sob tal concepção, o sistema é anterior à política e esta é uma instância controlável pelo primeiro" (ibid., p. 39). Esta perspectiva tem levado ao fracasso muitos sistemas de arquivos, já que os sistemas são produtos e não causas de uma política de arquivos.

O marco legal das políticas arquivísticas é a Lei n. ${ }^{\circ} 8.159$, de 8 de janeiro de 1991, conhecida como a Lei de Arquivos. As políticas públicas referentes à arquivística e à gestão de documentos começaram a ser concretizadas efetivamente após essa lei. Ainda que a preo- 
cupação com a organização e o acesso aos documentos públicos seja antiga, só recentemente foram dados passos decisivos nesse sentido (ARQUIVO NACIONAL, 2001).

Para Jardim (1995, p. 95), a "Lei de Arquivos apresenta características marcadamente conceituais, sobretudo no que se refere ao conjunto de definições apresentadas para termos como arquivos, gestão de documentos, arquivos públicos, documentos correntes, intermediários, permanentes, arquivos privados etc.". O mesmo autor salienta, ainda, que na lei é "assegurado o princípio de acesso do cidadão à informação governamental, bem como previsto o sigilo relativo a determinadas categorias de documentos"(p. 95). Outra contribuição da lei citada por Sousa (2006) é o estabelecimento da importância do documento de arquivo para a sociedade brasileira. No que diz respeito especificamente ao Arquivo Nacional, essa lei ampliou o seu raio de atuação enquanto principal instituição arquivística do país, a qual passa a desempenhar legalmente novas atribuições (SILVA, 1992).

Portanto, pode-se afirmar que o desenvolvimento das políticas arquivísticas públicas no Brasil é tardio, embora as várias iniciativas tenham obtido resultados positivos se forem considerados os parâmetros de países com desenvolvimento político-social semelhantes e o seu pouco tempo de existência. $\mathrm{Na}$ opinião de Camargo e Machado (2000), no Brasil, tem sido lenta a formulação ou aprovação de dispositivos legais que assegurem a gestão integral de documentos, principalmente nas administrações municipais.

A legislação arquivística desenvolveu-se muito nos últimos anos, sob vários aspectos. Mas só ela, por si só, não constitui política pública, como destaca Jardim (2008, p. 5): "a existência de textos legais que regulem uma atividade governamental não basta para identificarmos uma política pública". Há uma confusão frequente entre legis- lação e política arquivística. A legislação arquivística fornece elementos normalizadores à política arquivística, mas não é em si mesma uma política. Muitas vezes, a legislação arquivística tende a ser considerada o marco zero de uma nova era arquivística (JARDIM, 2003). Entretanto, a viabilidade dessa legislação se torna comprometida se não for simultaneamente instrumento e objeto de uma política arquivística (ibid).

Nesse sentido, cabe destacar que, no Brasil, é possível observar que as políticas de arquivos têm se limitado à elaboração de atos normativos (SOUSA, 2006). Sousa ressalta a dimensão técnico-científica, "que deve ser levada em consideração, pois a simples existência de leis ou de determinações não garante as ações concretas que a viabilizem" (2006, p. 8). O autor vai ao encontro do que lembra José Maria Jardim, que considera as duas dimensões - a política e a técnica - como faces de uma mesma moeda, acreditando que, somente com o exercício das duas, será possível formular e viabilizar políticas públicas arquivísticas (2003).

3.1 O Arquivo Nacional e o Conselho Nacional de Arquivos (CONARQ)

O Arquivo Nacional foi criado pelo art. 70 da Constituição do Império como "Arquivo Público do Império", com a finalidade de guardar toda lei assinada pelo Imperador. Sua regulamentação, no entanto, só ocorre em 1838 , quando foi integrado à Secretaria de Estado dos Negócios do Império (MATTAR, 2003). Em 1893, passa a denominar-se Arquivo Público Nacional e, em 1911, recebe a denominação atual. Hoje, está subordinado ao Ministério da Justiça. É o órgão central do Sistema de Gestão de Documentos de Arquivos (SIGA) da administração pública federal e tem como função dar suporte técnico ao Conselho Nacional de Arquivos (CONARQ). Assim, sua finalidade ${ }^{3}$ é:

${ }^{3}$ Fonte: http://www.arquivonacional.gov.br. 
implementar e acompanhar a política nacional de arquivos, definida pelo Conselho Nacional de Arquivos - Conarq, por meio da gestão, do recolhimento, do tratamento técnico, da preservação e da divulgação do patrimônio documental do País, garantindo pleno acesso à informação, visando apoiar as decisões governamentais de caráter político-administrativo, o cidadão na defesa de seus direitos e de incentivar a produção de conhecimento científico e cultural.

Nos últimos anos, o Arquivo Nacional vem prestando serviços de assistência técnica aos diversos órgãos governamentais, com o objetivo de contribuir para a racionalização e modernização dos serviços de arquivo; aperfeiçoar a recuperação da informação e minimizar o custo com a armazenagem; difundir as normas e os procedimentos arquivísticos; e conscientizar os órgãos quanto à responsabilidade perante a gestão documental (SILVA, 1992).

No Brasil, além do Arquivo Nacional, é o Conselho Nacional de Arquivos (CONARQ) que produz ações relacionadas à política nacional de arquivos. Esse conselho é o órgão central do Sistema Nacional de Arquivos (SINAR). O SINAR é integrado pelos arquivos da administração pública do Brasil em todos os seus níveis e pelas organizações privadas que estabelecerem um convênio com o Arquivo Nacional, órgão central do sistema.

O CONARQ foi criado pela Lei n. ${ }^{\circ} 8.159$, de 8 de janeiro de 1991 e regulamentado pelo Decreto n. ${ }^{\circ} 1.173$, de 29 de junho de 1994; sua instalação ocorreu em 15 de dezembro de 1994. A Política Nacional de Arquivos e a legislação brasileira são balizadoras das ações relacionadas à gestão da informação arquivística formuladas por esse conselho. Esse conselho deve se constituir na ligação entre o Estado e a Sociedade Civil no que se refere à gestão e ao direito à informação.
O CONARQ ${ }^{4}$ é constituído por 17 membros conselheiros: o Diretor-Geral do Arquivo Nacional, que o preside, e representantes dos poderes Executivo, Judiciário e Legislativo, do Arquivo Nacional, dos arquivos públicos estaduais e do Distrito Federal, dos arquivos públicos municipais, das instituições mantenedoras de curso superior de Arquivologia, de associações de arquivistas e de instituições que congreguem profissionais que atuam nas áreas de ensino, pesquisa, preservação ou acesso a fontes documentais. Cada conselheiro tem um suplente.

Além dos conselheiros, o CONARQ conta com Câmaras Técnicas com o objetivo de desenvolver estudos e normas necessárias à implementação da política nacional de arquivos públicos e privados e dar maior agilidade à operacionalização do SINAR. O CONARQ possui as seguintes Câmaras Técnicas: Câmara Técnica de Avaliação de Documentos; Câmara Técnica de Capacitação de Recursos Humanos; Câmara Técnica de Classificação de Documentos; Câmara Técnica de Conservação de Documentos; Câmara Técnica de Documentos Eletrônicos; e Câmara Técnica de Normalização da Descrição Arquivística.

O CONARQ possui, também, seis Câmaras Setoriais, que visam identificar, discutir e propor soluções para questões temáticas que repercutirem na estrutura e organização de segmentos específicos de arquivos, interagindo com as câmaras técnicas. São elas: Câmara Setorial sobre Arquivos de Empresas Privatizadas ou em Processo de Privatização; Câmara Setorial sobre Arquivos Médicos; Câmara Setorial sobre Arquivos do Judiciário; Câmara Setorial sobre Arquivos Municipais; Câmara Setorial sobre Arquivos de Arquitetura, Engenharia e Urbanismo; e Câmara Setorial sobre Arquivos Privados.

As iniciativas quanto às políticas públicas arquivísticas se devem, princi-

${ }^{4}$ Fonte: http://www.conarq.arquivonacional.gov.br. 
palmente, às ações e aos programas do Conselho Nacional de Arquivos (CONARQ) e do Arquivo Nacional. Esses órgãos têm procurado promover ações favorecedoras ao desenvolvimento do SINAR, propondo políticas, diretrizes e normas relativas à gestão de documentos de arquivo.

Quanto aos procedimentos de classificação e avaliação, a principal norma/ orientação é a publicação "Classificação, Temporalidade e Destinação de Documentos de Arquivo Relativos as Atividades-Meio da Administração Pública" (2001). O Código de Classificação e a Tabela de Temporalidade contidos nessa publicação são subsídios para a gestão dos documentos nos órgãos integrantes do Sistema Nacional de Arquivos no que diz respeito às atividades-meio. Esses instrumentos foram aprovados pela Resolução n. ${ }^{\circ} 4$, do CONARQ, e revisados e ampliados pelas Resoluções $n^{\circ}{ }^{\circ} 8$ de 1997 e n. $^{\circ} 14$ de 2001.

No estudo realizado por Faria (2006) sobre a normatização dos instrumentos de gestão arquivística, o autor destaca que a intenção do CONARQ com a elaboração desse Código e dessa Tabela foi produzir um modelo que servisse de referência para que os órgãos do poder público pudessem estabelecer seus próprios instrumentos de gestão. Salienta, ainda, que essa publicação permitiu aos órgãos ter a noção do funcionamento e da estrutura desses instrumentos de gestão arquivística.

Quanto à gestão de documentos eletrônicos, cabe citar, como exemplo dos estudos realizados, a publicação do Modelo de Requisitos para Sistemas Informatizados de Gestão Arquivística de Documentos (e-Arq Brasil). O e-Arq foi desenvolvido pela Câmara Técnica de Documentos Eletrônicos no período de 2004 a 2006 e apresenta os requisitos e metadados que devem ser utilizados no desenvolvimento ou na avaliação de sistemas informatizados de gestão de documentos. A Resolução n. ${ }^{\circ} 25$ do CONARQ recomenda a sua utilização por parte dos órgãos e entidades integrantes do Sistema Nacional de Arquivos. Recentemente, por meio da Resolução n. ${ }^{\circ}$ 32 foi aprovada a versão revisada e ampliada do e-Arq.

Jardim (2008) afirma que o CONARQ desenvolveu diversas ações técnico-científicas relevantes ao longo dos últimos anos. No entanto, "não formulou - como previsto na legislação - uma política nacional de arquivos e tampouco implementou, após onze anos de atuação, o Sistema Nacional de Arquivos" (p. 3). Segundo ele, isso evidencia as dificuldades estruturais do Estado brasileiro no desenho e na operacionalização de políticas públicas informacionais, pois existem aparatos legais e organizacionais e desenvolvimento de ações significativas por parte do CONARQ. A falta de consolidação do Sistema Nacional de Arquivos prejudica toda a sociedade, já que compromete o direito à informação e, consequentemente, à história social, além de afetar a eficiência governamental (ibid.).

Outra reflexão de Jardim que cabe destacar é que, apesar de ser um órgão colegiado, de caráter deliberativo, o CONARQ tem características de um órgão executor. Pode-se perceber isso, por exemplo, nas seguintes atribuições definidas no Decreto n. ${ }^{\circ} 4.073 / 2002$ : estabelecer diretrizes para o funcionamento do Sistema Nacional de Arquivos (SINAR); promover o inter-relacionamento de arquivos públicos e privados; subsidiar a elaboração de planos nacionais de desenvolvimento, estimular a integração e modernização dos arquivos públicos e privados; identificar os arquivos privados de interesse público e social, articular-se com outros órgãos do Poder Público formuladores de políticas nacionais nas áreas de educação, cultura, ciência, tecnologia, informação e informática etc. (JARDIM, 2008). 
3.2 O Sistema de Gestão de Documentos de Arquivo (SIGA) ${ }^{5}$

O Decreto n. ${ }^{\circ} 4915$, de 12 de dezembro de 2003, organiza, sob a forma de sistema, as atividades de gestão de documentos no âmbito dos órgãos e das entidades da administração pública federal (CONSELHO NACIONAL DE ARQUIVOS, 2011). Esse sistema é denominado Sistema de Gestão de Documentos de Arquivo (SIGA). Conforme $o$ art. $2^{\circ}$, o SIGA tem por finalidade:

I - garantir ao cidadão e aos órgãos e entidades da administração pública federal, de forma ágil e segura, o acesso aos documentos de arquivo e às informações neles contidas, resguardados os aspectos de sigilo e as restrições administrativas ou legais; II - integrar e coordenar as atividades de gestão de documentos de arquivo desenvolvidas pelos órgãos setoriais e seccionais que o integram; III - disseminar normas relativas à gestão de documentos de arquivo; IV - racionalizar a produção da documentação arquivística pública; V - racionalizar e reduzir os custos operacionais e de armazenagem da documentação arquivística pública; VI - preservar o patrimônio documental arquivístico da administração pública federal; VII - articular-se com os demais sistemas que atuam direta ou indiretamente na gestão da informação pública federal.

O SIGA é composto pelo órgão central, que é o Arquivo Nacional; pelos órgãos setoriais, que são as unidades responsáveis pela coordenação das atividades de gestão de documentos de arquivo nos Ministérios e órgãos equivalentes; e pelos órgãos seccionais, que são as unidades vinculadas aos Ministérios e órgãos equivalentes.

A Comissão de Coordenação do SIGA, de acordo com o disposto no art. $7^{\circ}$ do Decreto n. ${ }^{\circ} 4.915$, é composta pelo Diretor-Geral do Arquivo Nacional, que a presidirá; um representante do órgão ${ }_{5}^{5}$ Disponível em: <http://www.siga.arquivonacional.gov.br $>$. Acesso em: 25 mar. 2011. central, responsável pela coordenação do SIGA e designado pelo Diretor-Geral do Arquivo Nacional; um representante do Sistema de Administração dos Recursos de Informação e Informática (SISP), indicado pelo Ministro do Planejamento, Orçamento e Gestão; um representante do Sistema de Serviços Gerais (SISG), indicado pelo Ministro do Planejamento, Orçamento e Gestão; e os coordenadores das subcomissões dos Ministérios e órgãos equivalentes (CONSELHO NACIONAL DE ARQUIVOS, 2011).

Cabe aos Ministérios e aos órgãos equivalentes a criação de Subcomissões de Coordenação do SIGA que reúnam representantes dos órgãos seccionais de seu âmbito de atuação, com vistas a identificar necessidades e harmonizar as proposições a serem apresentadas à Comissão de Coordenação. Atualmente, segundo dados do site do SIGA, atualizados em fevereiro de 2010, o SIGA possui 36 subcomissões, dentre as quais está o Ministério da Educação. A subcomissão do Ministério da Educação conta com a participação de representantes dos diversos órgãos que o compõem, tais como as Secretarias, os Conselhos, os Hospitais Universitários e as Universidades.

Quanto às Universidades, vêm sendo realizadas diversas reuniões com vistas a normalizar e, principalmente, desenvolver um Código de Classificação e uma Tabela de Temporalidade e Destinação de Documentos de Arquivo relativos às atividades-fim das Instituições Federais de Ensino Superior (IFES). Com esse objetivo, realizou-se o I Workshop com as IFES, na sede do Arquivo Nacional, no Rio de Janeiro, em setembro de 2006. O tema do evento foi "Classificação, Temporalidade e Destinação de Documentos de Arquivo relativos às Atividades-fim", tendo participado do evento 45 técnicos das instituições de ensino, representando 31 instituições, além de 24 técnicos do Arquivo Nacional. Nesse evento, usou- 
se como base a Tabela de Temporalidade de Documentos da Universidade Federal da Paraíba, a fim de elaborar uma proposta única de Código de Classificação e Tabela de Temporalidade e Destinação de Documentos de Arquivo relativos às atividades-fim das IFES.

Entre maio de 2007 e junho de 2009, ocorreram seis Reuniões Técnicas de cinco dias cada, sendo cinco na sede do Arquivo Nacional, na cidade do Rio de Janeiro, e uma sediada pela UFPB, em João Pessoa. O objetivo dessas reuniões era dar continuidade à elaboração do Código de Classificação e da Tabela de Temporalidade e Destinação de Documentos de Arquivo Relativos às atividades-fim das IFES.

Em março de 2010, foi apresentada para consulta pública a proposta do Código de Classificação e da Tabela de Temporalidade e Destinação de Documentos de Arquivo relativos às atividades-fim das IFES. Conforme o regulamento, poderiam participar dessa consulta pública arquivistas, documentaristas, técnicos e especialistas em documentação escolar e atividades acadêmicas e demais profissionais que atuam nos arquivos gerais e setoriais das IFES. As manifestações poderiam ser encaminhadas à coordenação do SIGA, no período de 15 de março a 14 de maio de 2010 (o prazo foi prorrogado até 31 de maio). Até o presente momento, não foi publicada a versão final dessa Tabela.

Segundo esse regulamento, as classes e subdivisões do Código de Classificação de Documentos e da Tabela de Temporalidade e Destinação de Documentos de Arquivo relativos às atividades-fim das IFES têm suas bases na legislação e nas normas em vigor, em pesquisas e em estudos específicos. Destaca-se, ainda, que esse instrumento significa para as IFES o complemento ao Código de Classificação e à Tabela Básica de Temporalidade e Destinação de Documentos de Arquivo relativos às atividades-meio de 2001.

Dessa forma, fica evidente que os órgãos responsáveis pela Política Nacional de Arquivos têm demonstrado preocupação com os arquivos universitários e, por meio de grupos de trabalho, proporcionado algumas ações significativas, como a proposta do código de classificação e da tabela de temporalidade. A versão final desses instrumentos foi aprovada pela Portaria n..$^{\circ} 092$ do Arquivo Nacional, em 23 de setembro de 2011.

\section{Metodologia}

Este estudo se caracteriza como uma pesquisa descritiva, do tipo estudo multicasos, de cunho qualitativo. A revisão de literatura foi realizada visando aprofundar os conhecimentos referentes à temática e desenvolver a pesquisa com subsídios teóricos sólidos. O objetivo foi estruturar e desenvolver uma base teórica que concedesse sustentação ao desenvolvimento do trabalho (SILVA, 2005).

A internet foi utilizada para realizar a seleção das universidades a serem pesquisadas. Salienta-se que o objetivo da pesquisa é analisar a implementação das políticas públicas de gestão de documentos em universidades, descartando-se, portanto, os institutos e as demais Instituições de Ensino Superior (IES). Dessa forma, selecionaram-se as três primeiras instituições criadas no Rio Grande do Sul, conforme a análise do seu histórico nos seus respectivos sites: Universidade Federal do Rio Grande do Sul (1895); Fundação Universidade do Rio Grande (1953); e Universidade Federal de Santa Maria (1960).

Após a definição das instituições, foi enviada uma correspondência às mesmas, requerendo a autorização para a realização da pesquisa via mensagem eletrônica. Também foi realizada uma pesquisa nos sites para estudar o histórico e a estrutura de cada uma das universidades. Este estudo foi realizado a fim de contextualizar o universo da pesquisa.

$\mathrm{O}$ instrumento de coleta de dados escolhido é o questionário composto por questões abertas e fechadas. O questio- 
nário contém questões que abordam os seguintes assuntos: a identificação das instituições; as políticas arquivísticas já implementadas; o processo de gestão documental realizado na instituição; os instrumentos arquivísticos adotados; a observação/cumprimento das políticas públicas arquivísticas; o seu entendimento sobre os órgãos arquivísticos nacionais; e o seguimento ou não das orientações e da legislação arquivística nacional.

Para a validação do instrumento de coleta de dados, o questionário elaborado foi entregue a um profissional arquivista atuante na área de arquivos universitários para realizar uma análise e avaliação. $\mathrm{O}$ objetivo principal foi validar o instrumento quanto à clareza e objetividade das questões, no sentido de obter as respostas que permitissem a análise e o alcance dos objetivos propostos. A aplicação do pré-teste evidencia possíveis erros permitindo a reformulação da falha no questionário definitivo (LAKATOS; MARCONI, 2007). Assim, após análise do profissional, o instrumento foi aperfeiçoado considerando as suas sugestões.

Depois do recebimento da autorização para realizar a pesquisa nas instituições, foi realizada a aplicação dos questionários com os arquivistas responsáveis pelo setor de documentação da universidade, por meio do e-mail servidor designado pela Universidade. Para esse encaminhamento, foi utilizada a tecnologia de GED - repositório digital google doc, que permitiu a elaboração de um formulário eletrônico, obtendo-se, rapidamente, as respostas das três instituições.

Os dados coletados foram reunidos, analisados e discutidos teoricamente com base na fundamentação teórica. A análise e a interpretação são atividades distintas, porém estritamente relacionadas $-\mathrm{a}$ análise é a tentativa de evidenciar as relações existentes entre o assunto estudado e outros fatores, enquanto a interpretação é a atividade intelectual que procura dar um signifi- cado amplo às respostas, vinculando-as a outros conhecimentos (LAKATOS; MARCONI, 2007).

$\mathrm{Na}$ análise e interpretação dos resultados, as universidades foram identificadas com a letra $\mathrm{U}$ (universidade) e um número, do seguinte modo: U1 (Universidade 1), U2 (Universidade 2) e U3 (Universidade 3), conforme a ordem de recebimento das respostas, a fim de preservar suas identidades.

Durante a análise, foi realizada uma leitura preliminar, para destacar observações relevantes. Os dados foram organizados conforme as categorias para melhor compreensão dos resultados. As categorias de análise foram definidas de acordo com os objetivos da pesquisa. São elas: políticas arquivísticas; processo de gestão documental e instrumentos arquivísticos; políticas públicas arquivísticas; órgãos arquivísticos nacionais; e orientações e legislação arquivística. Neste artigo, são apresentados os resultados referentes às duas primeiras categorias de análise.

Para responder aos objetivos propostos, os resultados obtidos e analisados teoricamente permitiram apresentar as considerações finais do estudo. Os resultados desta pesquisa são apresentados na forma de uma monografia defendida no final do Curso de Especialização a Distância de Gestão em Arquivos da Universidade Federal de Santa Maria.

\section{Apresentação, análise e discussão dos resultados}

Neste artigo, são apresentados e analisados os resultados da pesquisa quanto às seguintes categorias de análise: políticas arquivísticas; e processo de gestão documental e instrumentos arquivísticos. Conforme a descrição da metodologia, na análise e interpretação dos resultados, as Universidades foram identificados como U1 (Universidade 1), U2 (Universidade 2) e U3 (Universidade 3). 


\subsection{Políticas arquivísticas}

No que se refere às políticas arquivísticas das universidades pesquisadas, é possível inferir que os arquivistas são os profissionais que respondem pelo estabelecimento das políticas arquivísticas, cumprindo com os dispositivos da Lei $\mathrm{n} .{ }^{\circ}$ 6.546 , de 4 de julho de 1978. Isso se evidencia porque, solicitada a participação do responsável pela gestão documental da instituição, todos os questionários foram respondidos por arquivistas.

A denominação do órgão responsável pela gestão de documentos/informações difere entre as Universidades. No que se refere à subordinação/vinculação do arquivo, todas as instituições são vinculadas à Pró-Reitorias ligadas às funções de Administração e Planejamento, havendo diferença apenas quanto à denominação utilizada para cada pró-reitoria. Isso pode representar, portanto, que a gestão de documentos/ informações está inserida na ordem das políticas e metas da administração universitária. Na concepção de Moreno (2006), os documentos arquivísticos são indispensáveis ao funcionamento de qualquer sociedade organizada, incluindo as universidades. A autora destaca, ainda, que os arquivos das universidades constituem uma ferramenta importante que deve ser gerenciada para propiciar o melhor desenvolvimento das atividades da organização.

Apenas a U2 declarou que não há sistema de arquivos instituído na Universidade. Cabe enfatizar as considerações de Silva, Santos e Viero (2009), em seus estudos sobre a criação de sistema de arquivos universitários: "A criação de sistemas de arquivos e de gestão documental é fundamental para a racionalização da produção documental e uso imediato e mediado das informações contidas no acervo" (p. 10). Também é importante destacar o pensamento de Silva $(1999$, p. 4), quando afirma que: "a realidade arquivística brasileira aponta, cada vez mais, para a necessi- dade de sistematização dos processos de tratamento, controle, guarda e acesso aos documentos". A despeito das tentativas empreendidas no setor público, em todos os níveis, é fato que as dificuldades para implantação de sistemas de arquivo nos órgãos públicos são inúmeras. Tais dificuldades compreendem desde a escassez de pessoal qualificado até a ausência de instrumentais básicos para a operacionalização dos sistemas, passando pela desatenção dos administradores para com os arquivos.

Apesar de todas as dificuldades apontadas por Silva (1999), as U1 e U3 possuem sistemas de arquivo instituídos, o que demonstra que a maioria das universidades federais do Rio Grande do Sul está consciente da relevância da institucionalização de sistemas de arquivos. A eficiência e a eficácia da gestão de documentos só é possível por meio da implementação de um sistema de arquivos.

Esses dados permitem afirmar que, nas instituições estudadas, há preocupação com a gestão de documentos/ informação e com a implementação de sistema de arquivos. Isso significa um primeiro passo para o desenvolvimento de políticas arquivísticas adequadas, como revela Moreno: "os arquivos universitários estão se reestruturando em todo o mundo para possibilitar o rápido acesso às informações armazenadas, de forma a apoiar as decisões político-administrativas, as pesquisas, à extensão etc.” (2006, p. 96).

5.2 Processo de gestão documental e instrumentos arquivísticos

Nesta categoria, apresenta-se a análise do processo de gestão documental das instituições e os instrumentos arquivísticos decorrentes das funções de classificação, avaliação e descrição, que são consideradas inseparáveis e complementares na perspectiva da arquivística integrada (LOPES, 1997).

De acordo com as respostas, a 
classificação de documentos não é realizada na U2. Nas U1 e U3, esta função é desenvolvida em alguns setores. $\mathrm{O}$ fato de a classificação não ser desenvolvida na totalidade das instituições merece reflexão, porque esta é uma função arquivística considerada primordial para o desenvolvimento das demais funções. No tocante aos documentos públicos, Sousa (2004) afirma que a classificação é a função matricial de todo o trabalho arquivístico, tendo um papel importantíssimo na preservação da memória da Administração Pública Federal, pois, por meio dela, é realizada a representação das informações. Consequentemente, o instrumento resultante do processo de classificação, o plano de classificação, foi elaborado para os documentos de alguns setores nas universidades $1 \mathrm{e}$ 3. O plano de classificação é o instrumento base da gestão de documentos: nele são representadas de forma hierárquica as unidades de classificação. Como bem ressalta Sousa (2004, p. 29):

a organização e o acesso às informações contidas nos documentos de arquivo não podem prescindir de um instrumento de gerenciamento do arquivamento dos registros documentais, pois a classificação das informações arquivísticas é uma atividade matricial, que fundamenta outras funções arquivísticas, tais como: avaliação e descrição.

Apesar de a U1 e a U3 realizarem a classificação documental, apenas a U1 afirma utilizar, parcialmente, o Código de Classificação de Documentos de Arquivo para a Administração Pública Federal: atividades-meio (ARQUIVO NACIONAL, 2001). A U2 e a U3 não o utilizaram nem mesmo como subsídio para desenvolver a classificação. O entrevistado da U3 esclarece que não concorda com a adoção de um instrumento de classificação padronizado para todos os órgãos da Administração Pública, como é possível notar na afirmação: "[...] a imposição do Código de
Classificação de Documentos e Tabela de temporalidade considero um desrespeito ao trabalho desenvolvido ao longo dos anos pelos arquivistas na Universidade".

Esse fato demonstra que o instrumento elaborado pela Câmara Técnica de Classificação de Documentos do CONARQ e aprovado por meio de Resolução não é totalmente utilizado na maioria das universidades pesquisadas, como recomendado pelos órgãos responsáveis pelas políticas públicas arquivísticas brasileiras.

Nas reflexões realizadas por Sousa (2004) quanto ao Código de Classificação de Documentos de Arquivo para a Administração Pública: atividades-meio, o autor questiona se é possível ter um instrumento de classificação padrão para um conjunto de órgãos públicos. Afirma, ainda, que a resposta a esse questionamento não é absoluta, pois cada órgão possui uma missão específica, o que o diferencia dos demais. No entanto, para o autor, as atividadesmeio desses órgãos são semelhantes em toda a administração pública, o que possibilitaria a adoção de um instrumento de classificação normalizado.

Sousa (2004) cita, também, a pesquisa de Oliveira (1997, p. 85), quando este afirma que, apesar de a maioria dos órgãos conhecerem as resoluções do CONARQ, "a utilização dos instrumentos aprovados é inexpressiva, além de não ter sido apontada como solução dos problemas por nenhum órgão". Essa afirmação revela que a não utilização do instrumento não ocorre só nas universidades pesquisadas, o que corrobora com a conclusão sobre sua inaplicabilidade. Para o autor, devido à sua complexidade estrutural, o Código constitui um instrumento de difícil entendimento.

Os estudos sobre o Código de Classificação de documentos apontam vários motivos para sua não utilização, mas os principais são: a classificação por assunto, a falta de reflexibilidade 
do Código, a não correspondência com a realidade informacional e a dualidade na interpretação. Sousa (2004) ressalta que o problema mais notório para a aplicação desses instrumentos publicados pelo CONARQ refere-se à sua estrutura, pois ocorre o uso inconsistente dos princípios de classificação ou divisão, quando há imprecisão na definição das funções e atividades, além da confusão entre a ação que produz o documento com o próprio documento.

Faria (2006, p. 21) destaca que há dois grupos distintos na comunidade arquivística nacional: "os que apóiam a iniciativa do CONARQ como forma de provocar as alterações necessárias no cenário arquivístico nacional; e os que repudiam o que foi entendido como "engessamento" dos principais instrumentos de gestão arquivística". Na sua pesquisa, Faria concluiu que é notória e determinante a contribuição das Resoluções $n^{\circ}{ }^{\circ} 4,8$ e 14 no desenvolvimento de ações arquivísticas, "seja pela reprodução integral de suas proposições ou pela base de pesquisa legislativa e técnica" (2006, p. 126).

Dessa forma, apesar das críticas e dificuldades apontadas, o Código de Classificação de Documentos de Arquivo para a Administração Pública: atividades-meio é considerado um importante instrumento que serve como subsídio para a realização da classificação nos órgãos da Administração Pública Federal. Faria (2006) e Sousa (2004) concordam que é indiscutível a importância da iniciativa do CONARQ de oferecer esse instrumento de classificação a ser adotado nos órgãos integrantes do Sistema Nacional de Arquivos. Para Sousa (2004, p. 51), "oferecer uma referência de instrumento de classificação de documentos de arquivo para os órgãos públicos federais é uma contribuição inestimável para reverter o cenário caótico apontado pela pesquisa do Arquivo Nacional".

No que se refere à avaliação documental, os resultados revelam que essa função é realizada em todas as universidades pesquisadas. Na U1, a avaliação já foi realizada em alguns setores e está em andamento em outros. A U3, por sua vez, afirma que a avaliação acontece somente em alguns setores. A $\mathrm{U} 2$, apesar de declarar que não realiza a classificação, afirma que o processo de avaliação documental está em andamento. Bernardes salienta que a avaliação deve "ser realizada no momento da produção, paralelamente ao trabalho de classificação, para evitar a acumulação desordenada, segundo critérios temáticos, numéricos ou cronológicos" (1998, p. 14). Neste sentido, reforça-se que, para que o processo de avaliação seja desenvolvido de forma satisfatória, é indispensável a realização da classificação, para melhor identificar e contextualizar os documentos.

Em todas as universidades pesquisadas, existem comissões permanentes de avaliação, mas não comissões setoriais. Nesse sentido, pode-se afirmar que todas as IFES pesquisadas cumprem o que dispõe o art. 18 do Decreto n. $^{\circ} 4.073$, de 3 de janeiro de 2002, que regulamenta a Lei n. ${ }^{\circ} 8.159$, de 8 de janeiro de 1991: "Em cada órgão e entidade da Administração Pública Federal será constituída comissão permanente de avaliação de documentos, que terá a responsabilidade de orientar e realizar o processo de análise, avaliação e seleção da documentação produzida e acumulada no seu âmbito de atuação, tendo em vista a identificação dos documentos para guarda permanente e a eliminação dos destituídos de valor".

No processo de avaliação, a comissão de avaliação de documentos é imprescindível. A avaliação documental é um processo que deve ter responsabilidades compartilhadas que recaiam sobre múltiplos sujeitos (HERNÁNDEZ OLIVERA; MORO CABERO, 2002). Cabe destacar que a U2 declara que a comissão não está atuando, apesar de o processo de avaliação estar em fase de desenvolvimento. Bernardes 
considera que o primeiro passo para a implementação do processo de avaliação de documentos de arquivo é a "constituição formal da Comissão de Avaliação de Documentos, que garanta legitimidade e autoridade à equipe responsável" (1998, p. 17). Assim, não é possível desenvolver um processo de avaliação adequado sem a participação de uma comissão de avaliação de documentos, considerando as normativas do CONARQ.

Com relação aos membros que compõem a comissão de avaliação, observa-se a participação de arquivistas em todas as comissões. $\mathrm{Na} \mathrm{U} 1$, fazem parte da comissão, além do arquivista, um administrador, um profissional da área jurídica, um historiador e um contador. Na U2, onde a comissão não está atuando, fazem parte um historiador, um docente do curso de Arquivologia e um representante do Hospital Universitário. Já na U3, a comissão é composta por um profissional da área jurídica, um técnico em microfilmagem e um responsável pela unidade produtora dos documentos.

O Arquivo Nacional (2001) orienta que a comissão de avaliação deve ser composta por: arquivista; servidores das unidades organizacionais às quais se referem os documentos a serem destinados; historiador ligado à área de pesquisa de que trata o acervo; profissional da área jurídica, responsável pela análise do valor legal; profissionais ligados ao campo de conhecimento de que trata o acervo (economista, sociólogo, engenheiro, médico e outros); e outros profissionais que possam colaborar com as atividades da comissão.

Dessa forma, as universidades em estudo não seguem totalmente as orientações do Arquivo Nacional. Na U1, observa-se a ausência de um colaborador da unidade produtora dos documentos. A U2, além da ausência do servidor da unidade produtora, também não há a presença de um profissional da área jurídica. Na U3, falta a presença de um historiador, que poderia garantir a preservação dos documentos de interesse histórico.

Cabe destacar ainda que, em se tratando de organizações complexas, seria indispensável a existência de comissões setoriais de avaliação. Isso facilitaria indiscutivelmente o processo de avaliação documental, pois essas comissões são responsáveis por: promover o levantamento e a identificação das séries documentais produzidas, recebidas ou acumuladas por seu respectivo órgão; elaborar a proposta de tabela de temporalidade, encaminhando-a para a apreciação e aprovação da comissão de avaliação; acompanhar os trabalhos de organização, racionalização e controle de documentos do seu setor, visando ao estabelecimento de rotinas de eliminação ou envio para guarda permanente; propor as modificações cabíveis para a tabela de temporalidade; coordenar o trabalho de seleção e preparação material dos conjuntos documentais a serem eliminados; entre outros (BERNARDES, 1998).

Quanto à tabela de temporalidade documental, instrumento resultante da avaliação, a U1 confirma a sua existência na instituição. Na U3, ela existe para alguns setores e está em fase de elaboração em outros. A U2 afirma que não possui esse instrumento. A tabela de temporalidade documental é um instrumento fundamental, porque permite distinguir as informações essenciais das supérfluas, garantindo a preservação, a recuperação e o acesso das informações, e torna a avaliação um procedimento organizado e seguro (SCHELLENBERG, 2006). A aplicação da tabela de temporalidade depende de duas tarefas: a normalização do fluxo documental e a conservação dos documentos (HERNÁNDEZ OLIVERA; MORO CABERO, 2002). Assim, ela é um instrumento imprescindível para a gestão de documentos tanto nas universidades como em qualquer instituição.

A ausência de instrumentos de 
gestão (como o plano de classificação e a tabela de temporalidade), em alguns setores das instituições, demonstra que o processo de gestão documental das universidades não cumpriu todos os seus objetivos. Para Rousseau e Couture (1998, p. 145), os instrumentos de gestão "facilitam o trabalho dos arquivistas e dos diversos intervenientes em matéria de análise e de definição de necessidades de acompanhamento e controle dos vários elementos do programa de gestão dos arquivos".

Quando questionadas sobre quais os subsídios utilizados para realizar a avaliação de documentos, todas as universidades declaram que utilizaram a Tabela de Temporalidade e Destinação de Documentos de Arquivo Relativos as atividades-meio da Administração Pública (ARQUIVO NACIONAL, 2001). Além desse instrumento, a U1 e a U3 responderam que utilizam como base o tempo de guarda estabelecido na legislação; a frequência de uso dos documentos; e os valores dos documentos. A U2 expõe que vem sendo utilizada também a "tabela das atividades-fim das IFES", denominada pelo SIGA como Tabela de Temporalidade e Destinação de Documentos de Arquivo Relativos às Atividades-Fim das Instituições Federais de Ensino Superior (IFES).

Esses dados permitem afirmar que o instrumento de avaliação elaborado para a Administração Pública Federal pelos órgãos responsáveis pelas políticas arquivísticas nacionais vem sendo utilizado, ainda que como subsídio. Desse modo, evidencia-se a relevância do trabalho do Arquivo Nacional e do Conselho Nacional de Arquivos de oferecer subsídios para que os órgãos da Administração Pública desenvolvam ações arquivísticas adequadas. Para Silva (1999), os atos normativos aprovados e disseminados pelo CONARQ vêm preencher graves lacunas que dificultavam a adequada gestão dos arquivos da administração pública.

As duas instituições que possuem tabela(s) de temporalidade(s), U1 e U3, consideram a orientação do Arquivo Nacional de enviar esse instrumento para a aprovação do órgão arquivístico na sua esfera de competência, como especifica a publicação "Classificação, Temporalidade e Destinação de Documentos de Arquivo Relativos às Atividades-Meio da Administração Pública" (2001, p. 43): "A tabela de temporalidade deverá contemplar as atividadesmeio e atividades-fim de cada órgão público. Desta forma, caberá aos mesmos definir a temporalidade e destinação dos documentos relativos às suas atividades específicas, complementando a tabela básica aqui apresentada. Posteriormente, esta deverá ser encaminhada à instituição arquivística pública para aprovação e divulgação, por meio de ato legal que lhe confira legitimidade".

Nesse sentido, a U1 declarou que a(s) tabela(s) de temporalidade da instituição foi(ram) encaminhada(s) e aprovada(s) pelo Arquivo Nacional; a U3 declarou que encaminhará a sua tabela para análise. A U2, como apresentado anteriormente, ainda não possui esse instrumento.

No que se refere à descrição documental, apenas uma das universidades, U2, afirma não possuir nenhum instrumento de pesquisa. A U1 declara que existe um catálogo para os processos administrativos, que não segue nenhuma norma, porque não foi elaborado pelo setor de Arquivo, e que também está sendo elaborado um catálogo para os arquivos setoriais, tendo como referência a Norma Brasileira de Descrição Arquivística (NOBRADE). A U3 respondeu que possui inventários documentais que foram elaborados tendo como subsídio a NOBRADE e instrumentos de pesquisa de outras instituições.

Ao analisar os resultados, observa-se que a NOBRADE foi utilizada por duas universidades, das três pesquisadas, para elaborar seus instrumentos de descrição. Dessa forma, é evidente 
a contribuição da norma/orientação do CONARQ no que se refere à descrição arquivística. Como afirma Andrade (2007), essa norma pode auxiliar as instituições a dar o primeiro passo, normalizando seus instrumentos de pesquisa. Assim, a NOBRADE vem cumprindo o seu objetivo, que é, conforme o art. $2^{\circ}$ da Resolução n. ${ }^{\circ} 28$ do CONARQ, a padronização de procedimentos em sistemas de arquivos e/ou em entidades custodiadoras e a facilitação do acesso e do intercâmbio de informações em âmbito nacional e internacional.

De acordo com as respostas, as três universidades não possuem um sistema de gerenciamento arquivístico para documentos eletrônicos da instituição nem fizeram menção ao uso de aplicativos ou banco de dados para gerenciar documentos. Esse resultado impede que se faça uma análise quanto à utilização do Modelo de Requisitos para Sistemas Informatizados de Gestão Arquivística de Documentos (e-Arq Brasil) e pode significar que as instituições não fazem uso de documentos eletrônicos, o que é muito pouco provável, ou que esses documentos não vem sendo tratados de forma adequada. Nesse sentido, cabe enfatizar que o CONARQ, na Carta para a Preservação do Patrimônio Arquivístico Digital, de 2004, manifesta "a importância das instituições arquivísticas, do poder público, da indústria de tecnologia da informação e comunicação e das instituições de ensino e pesquisa, implementarem ações" (CONARQ, 2010, p. 89, grifos nossos).

Com relação ao processo de gestão documental, a análise das políticas de gestão arquivística nas três universidades permite afirmar que muitas políticas arquivísticas vêm sendo adotadas e que há maior número de ações desenvolvidas na U1 e na U3, embora a U2 tenha declarado que muitos procedimentos estão em fase de implementação.

No entanto, observa-se, nas universidades pesquisadas, a falta de preo- cupação com o desenvolvimento do processo de gestão documental como um todo nas instituições, pois todas as funções arquivísticas desenvolvidas foram adotadas em apenas alguns setores. Tal resultado pode ser consequência da complexidade organizacional das IFES. Nesse sentido, é importante salientar que as ações devem se estender aos demais setores, até atingir toda a universidade, pois a gestão documental é um processo dinâmico e deve ser desenvolvido de forma contínua. Rousseau e Couture (1998) observam que a informação deve ser gerida sistematicamente, por meio de um programa organizado e harmonioso, que garanta a continuidade das intervenções arquivísticas. Essa dificuldade se apresenta nas universidades desde a década de 1990, porque, dentre as moções do I Seminário Nacional de Arquivos Universitários (1991), está a recomendação de que o processo de avaliação de documentos seja realizado em todas as unidades que compõem as universidades, por meio das comissões de avaliação locais e com a participação efetiva em todos os níveis.

Os resultados analisados permitem afirmar, também, que, de certa forma, os subsídios e as orientações do CONARQ e do Arquivo Nacional vêm sendo utilizados e observados para o desenvolvimento das ações arquivísticas nas três universidades pesquisadas. A Norma Brasileira de Descrição Arquivística é o instrumento mais utilizado e o Código de Classificação de Documentos de Arquivo para a Administração Pública: atividades-meio o menos utilizado. Esse resultado corrobora as considerações de Silva (1999), de que as ações do CONARQ e do Arquivo Nacional têm reflexos positivos que "já podem ser sentidos em ações concretas para o desenvolvimento de programas de gestão de documentos, tanto em órgãos e entidades da Administração Pública Federal, como em administrações estaduais" (p. 5). 
Indolfo (2008) concorda com essa opinião. Para a autora, a produção de normas arquivísticas voltadas para as atividades de gestão de documentos demonstra uma preocupação importante por parte dos órgãos arquivísticos nacionais, pois preenche lacunas na execução do tratamento técnico dos acervos arquivísticos públicos. Entretanto, as mudanças que se almejavam alcançar não ocorreram de forma rápida e expressiva, e as atualizações das normas ainda sofrem com fatores internos estruturais pelos quais passam, constantemente, as administrações públicas.

\section{Considerações finais}

Esta pesquisa teve como objetivo geral investigar a implementação de políticas públicas arquivísticas nas universidades federais do Rio Grande do Sul. Ao considerar esse objetivo e a análise dos resultados, pode-se concluir que as universidades em estudo aplicam em parte as políticas públicas arquivísticas.

No que diz respeito às políticas arquivísticas das instituições, é possível verificar que as universidades consideram importante o desenvolvimento de uma gestão de documentos/informações adequada aos princípios e às teorias arquivísticas. No caso dos arquivos universitários, a implementação da gestão da informação significa atender às necessidades informacionais de gestores, alunos, professores e pesquisadores. Ressalta-se a riqueza do acervo dessas instituições, que resguardam a prova de atividades de ensino, pesquisa e extensão.

A análise dos resultados permite afirmar que todas as universidades demonstraram interesse e disposição em desenvolver políticas arquivísticas de acordo com as normas vigentes. O reconhecimento da relevância de uma gestão documental adequada é o primeiro passo para mudar a realidade informacional das instituições, mas não é o suficiente. É necessário que gestores, ar- quivistas e servidores desenvolvam um trabalho em conjunto a fim de elaborar e executar projetos apropriados, para os quais sejam disponibilizados recursos humanos, materiais e financeiros.

A partir da análise do processo de gestão arquivística nas universidades, pode-se inferir que muitas políticas vêm sendo adotadas e, também, que há maior número de políticas sendo desenvolvidas nas universidades U1 e U3, embora U2 afirme que várias atividades estão em fase de planejamento. No entanto, observa-se a falta de preocupação com o desenvolvimento do processo de gestão documental como um todo nas instituições pesquisadas. À medida que se percebe a ausência de funções arquivísticas em alguns setores, entende-se que há muito a ser feito quanto ao processo de gestão documental nas IFES. Nesse sentido, recomenda-se que as ações sejam estendidas a todos os setores das instituições, porque é imprescindível que a gestão documental seja realizada uniforme e sistematicamente.

Quanto à utilização dos instrumentos de gestão elaborados pelo Conselho Nacional de Arquivos, esses são aplicados/utilizados parcialmente no âmbito das universidades pesquisadas. O Código de Classificação de Documentos de Arquivo relativos às atividades-meio (ARQUIVO NACIONAL, 2001) é o que apresentou maior grau de inaplicabilidade. A Tabela Básica de Temporalidade e Destinação Documentos de Arquivo Relativos às Atividadesmeio de 2001 é usada como subsídio para a realização da avaliação documental nas instituições. A NOBRADE é a norma mais utilizada pelas intuições como base para a elaboração de instrumentos de pesquisa.

Dessa forma, evidencia-se a importância desses instrumentos como subsídio para o estabelecimento e a aplicação de políticas arquivísticas nas Universidades. Ainda assim, devido às dificuldades de aplicação apresentadas, principalmente com relação ao Código 
de Classificação, sugere-se a revisão dos resultados, de forma conjunta com os diversos órgãos da Administração Pública Federal, para que melhor sejam representadas as funções e atividades desses órgãos. Apesar disso, cabe enfatizar que a tentativa de normatização dos instrumentos de gestão arquivística é uma questão delicada que causa discordância entre os autores da área. Por isso, deve haver um maior debate sobre a sua eficiência e o entendimento de que esses instrumentos servem apenas como subsídio para o desenvolvimento de ações arquivísticas e como um instrumento pronto para aplicação.

\section{Referências}

1. ANDRADE, R. S. Aspectos Introdutórios da Representação de Informação Arquivística: A Norma Brasileira de Descrição Arquivística (NOBRADE), A Descrição Arquivística Codificada (Ead-Dtd) e o Projeto Archives Hub 1. Revista eletrônica Ponto de Acesso, Salvador, v. 1, n. 2, abr. 2007. Disponível em: www.pontodeacesso.ici.ufba.br. Acesso em: 24 de mar. de 2010.

2. ARQUIVO NACIONAL (BRASIL). Conselho Nacional de Arquivos. Classificação, temporalidade e destinação de documentos de arquivo relativos as atividades-meio da administração pública. Rio de Janeiro: Arquivo Nacional, 2001.

$3 . \quad$ Dicionário brasileiro de terminologia arquivística. Rio de Janeiro: Arquivo Nacional, 2005.

4. BellotTo, H. L. Arquivística: objetos, princípios e rumos. São Paulo: AASP, 2002.

5. BERNARDES, I. P. Como avaliar documentos de arquivo. São Paulo: Arquivo do Estado, 1998. (Projeto como fazer; v.1).
6. CAMARGO, A. M. de A.; MACHADO, H. C. 2. ed. Como implementar arquivos públicos municipais. São Paulo: Arquivo do Estado, 2000. (Projeto como fazer; v. 3).

7. CASTANHO, D. M.; GARCIA, O. M. C.; SILVA, R. B. P. da. Arranjo e descrição de documentos arquivísticos. Santa Maria: Universidade Federal de Santa Maria, 2006.

8. CONSELHO NACIONAL DE ARQUIVOS. NOBRADE: Norma Brasileira de Descrição Arquivística. Rio de Janeiro: Arquivo Nacional, 2006.

9. FARIA, W. S. A normalização dos instrumentos de gestão arquivística no Brasil: um estudo da influencia das Resoluções do Conarq na organização dos arquivos da Justiça Eleitoral Brasileira. 2006. 147 f. Dissertação (Mestrado em Ciência da Informação) - Universidade de Brasília, Brasília, 2006. Disponível em: http://repositorio. bce.unb.br/bitstream/10482/2757/1/ Dissert $\% 20$ Wadson $\% 20$ Silva $\% 20$ Faria.pdf. Acesso em: 23 de mar. de 2010.

10. GONÇALVES, J. Como classificar e ordenar documentos de arquivo. São Paulo: Arquivo Nacional, 1998. (Projeto como fazer, v.2).

11. HERNÁNDEZ OLIVERA, L.; MORO CABERO, M. Procimientos de valoración documental. Salamanca: ACAL, 2002.

12. INDOLFO, A. C. As transformações no cenário arquivístico federal a partir do uso das normas. In: Anais do Congresso Brasileiro de Arquivologia, 2008, Goiânia. Disponível em: http://www.aag.org.br/anaisxvcba. Acesso em: 13 de abr. de 2010.

13. JARDIM, J. M. O inferno das boas intenções: legislação e políticas arquivísticas. In. MATTAR, Eliana. Acesso à informação e política de arquivos. Rio de Janeiro: Arquivo Nacional, 2003.

14. Políticas públicas arqui- 
vísticas: princípios, atores e processos Arquivo \& Administração, Rio de Janeiro, v. 5, n. 2, p. 5-16, 2006.

15. JARDIM, J. M. Políticas públicas de informação: a (não) construção da política nacional de arquivos públicos e privados (1994-2006). Disponível em: http://www.enancib2008.com.br/ Acesso em: 25 de ago. de 2009.

16. Sistemas e políticas públicas de arquivos no Brasil. Niterói: EDUFF, 1995.

17. LAKATOS, E. M.; MARCONI, M. A. Fundamentos da Metodologia científica. 6. ed. São Paulo: Atlas, 2007.

18. LOPES, L. C. A gestão da informação: as organizações, os arquivos e a informática aplicada. Rio de Janeiro: APERJ, 1997.

19. MATTAR, E. (org.). Acesso à informação e política de arquivos. Rio de Janeiro: Arquivo Nacional, 2003.

20. MORENO, N. A. A informação arquivística no processo de tomada de decisão em organizações universitárias. 2006. 220f. Tese (Doutorado em Ciência da Informação) - Escola de Ciência da Informação, Universidade Federal de Minas Gerais, Belo Horizonte, 2006. Disponível em: http://dspace. lcc.ufmg.br. Acesso em: 13 de abr. de 2010.

21. ROUSSEAU, J.-Y.; COUTURE, C. Os fundamentos da disciplina arquivística. Lisboa: Publicações Dom Quixote, 1998. (Nova Enciclopédia, 56).

22. SCHELLENBERG, T. R. Arquivos modernos: princípios e técnicas. $6^{\circ}$ ed. Rio de Janeiro: Ed. FGV, 2006.

23. SILVA, E. L. Metodologia da pesquisa e elaboração de dissertação. $4^{\mathrm{a}}$. ed. rev. atual. Florianópolis: UFSC, 2005.

24. SILVA, J. A. O Arquivo Nacional e a política nacional de arquivos. In: Seminário Nacional de Arquivos Universitários, I, 1991, Campinas. Atas...
Campinas: Coordenadoria do Sistema de Arquivos da Universidade Estadual de Campinas, 1992.

$25 . \quad$. Por uma Política Nacional de Arquivos. In: Mesa Redonda Nacional de Arquivos, 1999. Disponível em: www.conarq.arquivonacional.gov.br/.../ por uma poltica nacional de arquivos.pdf. Acesso em: 13 de abr. de 2010.

26. SILVA, R. C. P.; SANTOS, A. G.; VIERO, T. V. Políticas Arquivísticas para Implantação de um Sistema de Arquivos e Gestão Documental na Universidade Federal de Rio Grande (Furg). In: Congreso de Archivología del MERCOSUR, VIII, Reunión de Archivos Universitários, VI, 2009, Montevideo. Disponível em: http://www.fder. edu.uy/contenido/archivo-historico. Acesso em: 18 de mai. de 2010.

27. SOUSA, R. T. B. O arquivista e as políticas públicas arquivísticas. In: Congresso Nacional de Arquivologia, II, 2006, Porto Alegre. Anais... Porto Alegre: Associação dos Arquivistas do Estado do Rio Grande do Sul, 2006.

28. . O Código de Classificação de Documentos de Arquivo do Conselho Nacional de Arquivos: estudo de caso de um instrumento de classificação. Revista do Arquivo de Rio Claro, Rio Claro, $n^{\circ}$. 2, p. 26-69, 2004. Disponível em: http://repositorio.bce.unb.br/ handle/10482/1430. Acesso em: 13 de abr. de 2010 .

29. ZURITA, O. N. Influencia de la gestión administrativa en un Archivo Universitario. In: Congreso de Archivología del MERCOSUR, VIII, 2009, Montevideo. Disponível em: http://www.fder.edu.uy/contenido/archivo-historico/ponencias/ar-zurita.pdf. Acesso em: 18 de mai. de 2010. 